\title{
A educação escolar no meio rural do município de Ituiutaba-MG, Brasil: Educação Rural ou Educação do Campo? ${ }^{\mathrm{i}}$
}

\begin{abstract}
Astrogildo Fernandes da Silva Júnior ${ }^{1}$, Marcos Flávio Alves Leite ${ }^{2}$
${ }^{1}$ Universidade Federal de Uberlândia - UFU. Faculdade de Ciências Integradas do Pontal. Programa de PósGraduação em Educação. Rua 20, 1600, Bairro Tupã, Ituiutaba - MG. Brasil. silvajunior_af@yahoo.com.br.

${ }^{2}$ Universidade Federal de Uberlândia - UFU
\end{abstract}

RESUMO. Este artigo tem como objetivo apresentar algumas reflexões sobre a história da educação efetivada no meio rural brasileiro, priorizando diferenciar o paradigma da educação rural do paradigma da educação do campo; mapear a produção acadêmica que trata da temática investigada e, por fim, empreender um olhar sobre o cenário da investigação: o município de Ituiutaba-MG, Brasil. Quanto à metodologia recorreu-se a uma revisão bibliográfica abordando a educação rural e educação do campo, pesquisa inspirada no Estado da Arte, levantamento e análise documental realizados na Secretaria Municipal de Educação de Ituiutaba-MG, Brasil. Concluiu-se que a educação que se efetiva nas escolas localizadas no meio rural daquela cidade mantém as características do paradigma da Educação Rural.

Palavras-chave: Educação Rural, Educação do Campo, Escolas Rurais. 


\title{
School education in the rural environment of Ituiutaba- MG, Brazil: Rural Education or Countryside Education?
}

\begin{abstract}
This paper aims to present some reflections on the history of education introduced in the Brazilian rural environment. The objectives are as follows: to differentiate the paradigm of rural education from the one of the rural area; to map the academic production on the research topic and, finally, to look at the scenario of this investigation: Ituiutaba-MG, Brazil. The methodology involved a bibliographical review, research of the State of Art, documentary analysis carried out at the Municipal Secretary of Education of Ituiutaba. The results reveal that the education that takes place in the rural schools located in Ituiutaba maintains the characteristics of the Rural Education paradigm.
\end{abstract}

Keywords: Rural Education, Countryside Education, Rural Schools. 


\section{Educación escolar en las zonas rurales del municipio Ituiutaba-MG, Brasil: La Educación Rural o Educación del Campo?}

RESUMEN. Este artículo tiene como objetivo presentar algunas reflexiones sobre la historia de la educación efectiva en el Brasil rural, dando prioridad a diferenciar el paradigma de la educación rural paradigma de la educación rural; Mapa de la literatura académica tratar el tema investigado $\mathrm{y}$, por último, echar un vistazo a la etapa de investigación: la ciudad de Ituiutaba-MG, Brasil. En cuanto a la metodología se utilizó una revisión de la literatura frente a la educación rural y la educación rural, la investigación inspirado en el estado de la técnica de análisis, el estudio y el documento realizado en el Municipal Ituiutaba-MG de Educación, Brasil. Se concluyó que la educación sea efectiva en las escuelas ubicadas en las zonas rurales de la ciudad sigue siendo el paradigma de las características de la educación rural.

Palabras clave: Educación Rural, Educación del Campo, Las Escuelas Rurales. 


\section{Introdução}

Ao longo dos últimos anos empreendemos estudos sobre a educação que se efetiva em diferentes escolas localizadas no meio rural em diversos municípios do Estado de Minas Gerais. Nesse processo estabelecemos diálogos com gestores, professores e jovens estudantes que estudavam e viviam no campo, analisamos documentos curriculares, o Projeto Político Pedagógico (PPP) das escolas e vivenciamos o cotidiano escolar. De forma recorrente, procuramos identificar qual educação estava sendo oferecida, e que concepção estava presente nessa oferta: o paradigma da educação rural ou da educação do campo? Ou seja, um ensino que não considera as especificidades de seus sujeitos, do tipo compensatório, ou uma educação no sentido amplo de processo de formação humana, que constrói referências culturais e políticas para a intervenção das pessoas na realidade, voltada ao interesse do campo.

As pesquisas realizadas revelaram que o espaço rural não se limitava em ter como atividade econômica dominante a agricultura, nem como função principal produzir alimentos. Conforme Silva Júnior (2007) o mundo rural como categoria histórica se transformou, ao longo do tempo, num espaço diverso, plural nos aspectos sociais, econômicos, históricos e culturais. O mundo rural é maior que o mundo agrícola. As escolas investigadas passaram pelo processo de nucleação. Foram construídas em pontos estratégicos, e a maior parte dos estudantes e professores utilizava o transporte escolar oferecido pelas prefeituras municipais. Os livros didáticos eram os mesmos utilizados nas escolas do meio urbano; o currículo e o calendário escolar consistiam em arremedo da cidade. Práticas pontuais de alguns professores consideravam as especificidades do campo. Enfim, as pesquisas iniciais revelaram sinais do grande desafio de pensar em propostas para que o paradigma da Educação do Campo se efetive nas escolas mineiras localizadas no meio rural.

Com o intuito de aprofundar o conhecimento sobre as diferentes realidades experienciadas em escolas localizadas no meio rural, estamos desenvolvendo um projeto de pesquisa aprovado pelo $\mathrm{CNPq}$ Chamada Universal MCTI/CNPq $n^{\circ}$ 01/2016, intitulado: "Ensinar e Aprender História: um estudo em escolas localizadas no meio rural do município de Ituiutaba, MG, Brasil”. No decorrer do projeto, trinta e seis meses, propomos os objetivos: refletir sobre as mudanças e permanências que marcaram a 
história da educação que se efetivou no meio rural do município de Ituiutaba-MG, Brasil, buscando compreender o impacto da nucleação e municipalização das escolas rurais; mapear a produção acadêmica da temática Educação Rural e Educação do Campo, procurando identificar os objetivos e as metodologias adotadas nas diferentes pesquisas; diagnosticar como os professores de História ensinam e como os estudantes aprendem História no cotidiano da sala de aula; apresentar o perfil dos professores e estudantes, sujeitos da pesquisa; conhecer as fontes e linguagens preferidas dos jovens estudantes e as mais utilizadas pelos professores; produzir materiais didáticos, recorrendo a diferentes fontes e linguagens, considerando as especificidades de ensinar e aprender História em escolas localizadas no meio rural, bem como a proposta da Educação do Campo; produzir, organizar e divulgar interpretações dos materiais didáticos produzidos e desenvolvidos nas aulas de História das escolas localizadas no meio rural do município de Ituiutaba-MG, Brasil; contribuir para subsidiar estudos e pesquisas sobre a educação em escolas localizadas no meio rural, bem como sobre o processo de ensinar e aprender História, fornecendo dados para os cursos de graduação, pós-graduação e pesquisadores da área.
Nos limites deste texto propomos apresentar algumas reflexões sobre a história da educação efetivada no meio rural brasileiro, priorizando diferenciar o paradigma da educação rural do paradigma da educação do campo; mapear a produção acadêmica que trata da temática investigada e, por fim, empreender um olhar sobre o cenário da investigação: o município de Ituiutaba-MG, Brasil. As metodologias adotadas nessa primeira fase da investigação consistiram em revisão bibliográfica abordando a educação rural e educação do campo, pesquisa inspirada no Estado da Arte, levantamento e análise documental realizada na Secretaria Municipal de Educação de Ituiutaba-MG, Brasil.

Olhares sobre a história da educação efetivada no meio rural brasileiro: a Educação do Campo como possibilidade

Inicialmente recorremos a um levantamento bibliográfico sobre as temáticas "educação rural" e "educação do campo". Concordamos com Barros (2011) ao afirmar que a pesquisa bibliográfica se faz necessária, pois ninguém inicia uma reflexão científica a partir do marco zero. É fundamental que o pesquisador considere as conquistas ou questionamentos que já foram levantados em trabalhos anteriores, para estabelecer um diálogo ou problematizar. 
Os estudos revelaram que a constituição e consolidação do sistema escolar no Brasil pautam-se em um paradigma urbano. De acordo com Silva e Silva Júnior (2012), foi-se construindo, ao longo da primeira metade do século $\mathrm{XX}$, uma representação disseminada entre os profissionais da educação de que a população rural não interessava pela escola. Assim, efetivou-se uma idealização da cidade como espaço civilizatório, expressão da dinâmica política, cultural e educativa. Como consequência, o paradigma urbano se tornou inspiração do direito à educação. Para Arroyo (2007, p. 159), a palavra adaptação, recorrente nas políticas e nos ordenamentos legais, reflete que o campo é lembrado como o outro lugar, os povos do campo como outros cidadãos e a escola e seus educadores, são outros. Essa construção histórica na qual o Campo é subsumido ao paradigma urbano, considerado como resíduo, pode ser evidenciada ao longo da história do sistema de ensino no Brasil.

Segundo Silva Júnior e Borges Netto (2011), a escola rural, no Brasil, foi construída tardiamente e sem apoio do Estado para que se desenvolvesse. A Educação Rural não foi mencionada nos textos constitucionais até 1891. Tal afirmação revela o descaso das elites dominantes com as escolas rurais. Os autores recorrem ao Grupo Permanente de Trabalho de Educação do Campo (GPTE), instituído pelo Ministério da Educação, em 3 de junho de 2003, que denunciam a omissão do Estado brasileiro na formação de diretrizes políticas e pedagógicas específicas que regulamentassem o funcionamento das escolas do campo; a ausência de apoio financeiro que possibilitasse a manutenção de uma escola de qualidade em todos os níveis de ensino e a carência de políticas efetivas de formação inicial e continuada e de valorização da carreira docente no campo.

Segundo Araújo (2006), desde o século XIX já se evidenciavam intenções pontuais de dotar as populações rurais de escolas, mas, somente a partir de 1930, ocorreram programas de escolarização relevantes para as populações rurais. Porém, os resultados práticos ainda não se manifestaram inteiramente, no sentido de fornecer uma conformação especial às instituições escolares. Segundo a autora, nos anos de 1930, a formação do professor para o ensino rural era citadina. Era necessário, pois, criar um tipo de professor para o meio rural. A escola normal rural deveria formar um profissional entendido de agricultura, de enfermagem, ser um incentivador do progresso.

Consoante com Araújo (2006), no Ceará, foi fundada a primeira Escola 
Normal Rural do Brasil. Juazeiro do Norte foi o município pioneiro com o papel de levar a "luz" do conhecimento para as terras secas dos campos cearenses. A fundação de uma escola em defesa de uma ação educadora que atingisse os sertões cearenses era amparada por educadores como Lourenço Filho e Sud Mencci. Ainda conforme Araújo (2006) as professoras formadas nas escolas normais rurais cearenses buscaram fazer o que podiam para realizar a "missão" educativa. $\mathrm{Na}$ prática, a educação no campo em quase nada foi alterada.

Para Silva Júnior (2007), ao longo do processo de reforma de ensino no Estado de Minas Gerais, em 1927, fortaleceu-se o debate que defendia o dualismo na educação mineira. A proposta era de um modelo de escola para a cidade e outro para o meio rural, e neste havia dois posicionamentos: enquanto um grupo defendia que a escola deveria ensinar a ler e a escrever nos dois primeiros anos e, nos dois anos seguintes, ensinar técnicas agrícolas, o outro grupo propunha uma escola que tivesse um calendário adaptado ao meio rural, mas que ensinasse o mesmo que no meio urbano. Ambos os grupos concordavam em que o papel da escola era diminuir o êxodo rural. Podemos observar que a preocupação não era com um ensino de qualidade, mas com o êxodo rural e suas consequências. $\mathrm{O}$ intuito do ensino oferecido era acabar com o analfabetismo e tornar o cidadão do campo "civilizado". Por volta de 1930 a educação escolar no meio rural em Minas Gerais tinha a função de ensinar hábitos de higiene e outros valores. Aprender a ler e escrever ficava relegado a segundo plano.

As transformações ocorridas na educação escolar no meio rural, no período entre 1930 a 1964, não registraram grandes mudanças efetivas no cenário nacional. A Constituição de 1934 apresenta, no artigo 156, que a União deveria reservar, no mínimo, vinte por cento das cotas destinadas à educação, no respectivo orçamento anual, para a realização do ensino nas zonas rurais. O PNE de 1934 definiu para o meio rural uma política pautada no controle do êxodo rural e na aculturação do homem do campo. Outro aspecto do PNE foi a descentralização, em que a responsabilidade pelos níveis de ensino foi dividida entre a União, Estado e Municípios. O Estado de Minas Gerais, assim como os demais Estados Federados, ficou responsável pelo ensino primário, ginasial e secundário; a rede de ensino no meio rural passou a ser de responsabilidade dos municípios.

Quanto à Constituição de 1937, nada mencionou sobre a educação no meio rural. Nesse contexto, segundo Leite (1999), foi 
criada a Sociedade Brasileira de Educação Rural, com o objetivo de expansão do ensino e preservação da arte e folclore rurais. Em 1942 a escolarização rural foi reforçada durante o VIII Congresso Brasileiro de Educação, porém, de acordo com Leite (1999), não se definiram, claramente, os óbices da educação rural. A Constituição de 1946 também silenciou sobre a questão no meio rural. Flores (2000), ao analisar a LDB $\mathrm{n}^{\circ} 4.024 / 61$, afirma que o processo de tramitação da Lei acirrou as discussões a respeito da responsabilidade do Estado para com a educação do país. Porém, o debate que se configurou nesse período não foi suficiente para garantir as escolas para o meio rural. Sobre essa Lei, Leite (1999) declara que, ao deixar a cargo das municipalidades, a estruturação da escola fundamental no meio rural foi omitida, uma vez que a maioria das prefeituras municipais do interior era desprovida de recursos humanos e financeiros.

O olhar sobre a história da educação efetivada no meio rural brasileiro nos permite concordar com Silva Júnior e Borges Netto (2011), ao denunciarem que a educação no meio rural não se constituiu em espaço prioritário para ações planejadas do Estado Brasileiro. Assim, a população do campo não teve acesso às políticas e serviços públicos em geral. Tal fato contribuiu para o acelerado processo de êxodo rural, registrado a partir dos anos de 1950. Segundo os autores, o êxodo rural foi resultado de dois fenômenos: expulsão e atração. A expulsão aconteceu decorrente da modernização conservadora do Campo, que privilegiou os grandes latifundiários, não incluindo $\mathrm{o}$ agricultor familiar. A atração que as cidades exerceram no processo de industrialização era, não raro, uma visão idílica, que não correspondia à realidade dos trabalhadores do Campo.

O descaso do Estado em relação à educação escolar no meio rural, fez com que as próprias comunidades se mobilizassem para criar escolas e garantir a educação dos filhos dos trabalhadores que vivam em espaços rurais. Nesse processo, contaram algumas vezes com o apoio da igreja e movimentos sociais comprometidos com a educação popular. Essas experiências foram abortadas no o golpe militar no Brasil, em 1964. De acordo com Silva Júnior e Borges Netto (2011), os movimentos de participação e representação popular foram fechados, impedindo a manifestação dos grupos envolvidos. Houve perseguição, prisão e exílio de educadores comprometidos com os projetos de educação popular. Esse período foi caracterizado por uma reforma educacional centralizadora e excludente 
ancorada no binômio segurança nacional e desenvolvimento econômico.

Ao longo do período da ditadura militar no Brasil, a lei que regeu a educação escolar foi a Lei Federal $n^{\circ}$ 5.692/71. Leite (1999, p. 26) ressalta algumas intenções implícitas da Lei: de utilizar o processo escolar, em todos os níveis, como um meio de propagar e divulgar o ideário nacionalista-militar do Estado; efetivar o controle políticoideológico-militar, principalmente da classe operária, por meio da profissionalização, ou seja, de um currículo escolar mínimo desprovido de conteúdos críticos; recriar uma infraestrutura material e de recursos humanos adequados ao desenvolvimento do capital. Em relação às especificidades da Educação Rural. O autor declara que ela não foi focalizada ou enfatizada, mas, sim, destituída de sua identidade.

Segundo Silva Júnior e Borges Netto (2011), a partir dos anos de 1970, as reações ao autoritarismo implantado pelo golpe militar cresceram na sociedade brasileira. Passaram a pensar em outras possibilidades para a escola rural, agora em uma perspectiva crítica. Diferentes iniciativas, situadas no campo da educação popular, exigiram maior participação do Estado no mundo rural brasileiro. Os debates se acirraram com a aprovação da
Constituição Federal de 1988 e da LDB, Lei de Diretrizes e Bases da Educação Nacional (LDB $n^{\circ}$ 9.394/96), que propõe no art. 28:

Na oferta da educação básica para a
população rural, os sistemas de
ensino promoverão as adaptações
necessárias a sua adequação às
peculiaridades da vida rural e de cada
região, especialmente: I - conteúdos
curriculares e metodologias
apropriadas às reais necessidades e
interesses dos alunos da zona rural; II
- organização escolar própria,
incluindo adequação do calendário
escolar às fases do ciclo agrícola e às
condições climáticas; III - adequação
à natureza do trabalho na zona rural
(Brasil, 1997).

Ao refletir sobre o artigo, evidenciamos a proposta de adequação da escola à vida Campo. A LDB permite ações que considerem as especificidades do mundo rural. Desvincula a escola rural da escola urbana. Porém, é possível retomar as críticas de Arroyo (2007) no que se refere aos termos "adaptação", "adequação", ou seja, a escola no meio rural era vista como "outra"; nesse sentido hierarquicamente inferior. Além disso, Leite (1999, p. 55) afirma que a problemática ligada à escola rural permaneceu e acrescenta outros problemas a serem superados, principalmente após o processo de nucleação, ocorrido a partir dos anos de 1990, que reuniam várias escolas isoladas: a distância entre a residência dos estudantes e a escola, a 
condição do aluno como trabalhador rural; pouca participação da comunidade no processo escolar; permanência de um currículo que não considera as especificidades do meio rural, etc.

A educação escolar efetivada no meio rural brasileiro continuou não incorporando as demandas trazidas à sociedade pelos movimentos sociais. Dessa forma, assistimos a presença constante dos sujeitos do Campo na cena política e cultural do país. De acordo com Arroyo, Caldart e Molina (2004), esses sujeitos se mostram diferentes e exigem respeito; denunciam o silenciamento e o abandono por parte de órgãos do governo e lutam por uma escola do campo que não se configure como um arremedo da escola urbana, mas que esteja atenta aos sujeitos que vivem no campo.

As lutas sociais, empreendidas por organizações sociais, revelam que se faz necessário um olhar para aqueles que foram segregados de uma educação de qualidade. No caso de uma educação de qualidade no e do Campo, deve ser compreendida como uma educação que promova ações e estratégicas para a emancipação e cidadania de todos os sujeitos que vivem no campo. Uma educação que colabore para a formação das crianças, jovens e adultos para o desenvolvimento sustentável regional e nacional. Segundo Arroyo, Caldart e Molina (2004) é possível e necessário levar em conta os saberes que a população rural produz nas suas experiências cotidianas. Uma política de educação do Campo deve incorporar problematizações a respeito das diferenças culturais. Segundo os autores,

A educação é um direito social. Uma política de Educação do Campo requer o reconhecimento de que a cidade não é superior ao campo e, a partir dessa compreensão, devem-se impor novas relações baseadas na horizontalidade e solidariedade entre campo e cidade. O campo é, acima de tudo, espaço de cultura singular, rico e diverso. Assim, é importante a superação da dicotomia entre o rural e o urbano (Arroyo, Caldart \& Molina, 2004, p. 26).

Para Silva Júnior e Borges Netto (2011), para qualificar os debates e embates acerca da identidade da educação escolar rural, é importante considerar a diferenciação entre o paradigma da Escola Rural do paradigma da Escola do Campo. Segundo Silva e Costa (2006), o paradigma da Educação Rural não se propõe a fazer as inter-relações emergentes da sociedade brasileira. Não busca incorporar as demandas trazidas à sociedade pelos movimentos sociais e sindicais, que exigem a valorização das especificidades do meio rural. Os trabalhadores rurais e suas técnicas são vistos como improdutivos, excluídos e seus territórios não existem, porque não são entendidos 
como territórios de vida. O paradigma da Educação do Campo concebe o campo como espaço de vida e resistência, onde camponeses lutam por acesso a terra e pela oportunidade de permanecer nela. Concebe a diversidade dos sujeitos sociais agricultores, assentados, ribeirinhos, caiçaras, extrativistas, pescadores, indígenas, remanescentes de quilombos, enfim, todos os povos do Campo brasileiro. Reconhece a importância da agricultura familiar ao reconhecer a diversidade do Campo brasileiro.

Nesse contexto de reivindicações o GPTE (2005) defende os seguintes princípios pedagógicos de uma Educação do Campo:

o papel da escola é: $1^{\circ}$ ) formar sujeitos, e isso deve articular-se a um projeto de emancipação humana; $2^{\circ}$ ) valorizar os diferentes saberes oriundos da diversidade de sujeitos no processo educativo; $3^{\circ}$ ) valorizar os diferentes espaços e tempos de formação dos sujeitos da aprendizagem, pois a educação no campo ocorre tanto em espaços escolares quanto fora deles; $4^{\circ}$ ) vincular a escola à realidade dos sujeitos; $5^{\circ}$ ) ter a educação como estratégia para o desenvolvimento sustentável; $6^{\circ}$ ) desenvolver a autonomia e colaboração entre os sujeitos do Campo e o sistema nacional de ensino (Brasil, 2005, p. $10)$.

Com base nesses princípios, a discussão em torno do ensino em escolas rurais ganha relevância. Discutir sobre o demandam novas análises, novos ângulos e novas perspectivas.

\section{Educação do Campo e Educação Rural: o que dizem as produções acadêmicas}

Como afirmamos anteriormente, nenhuma pesquisa inicia-se do marco zero. Consideramos fundamental dialogar com outros autores com diferentes produções que abordem a mesma temática. É importante apresentar o que foi produzido, até mesmo para refletir sobre nossa contribuição sobre o tema. Dessa forma, realizamos uma pesquisa inspirada no estado da arte ou do conhecimento, que visou levantar, organizar e analisar a produção acadêmica sobre as temáticas "Educação Rural" e "Educação do Campo" no período de 2007 a 2017. Concordamos com Ferreira (2002) ao afirmar que as pesquisas denominadas "estado da arte" são caracterizadas por um caráter biográfico e têm como desafio mapear e discutir uma determinada produção acadêmica em diferentes campos do conhecimento, realizando uma metodologia de caráter inventariante e descritivo da produção acadêmica e científica sobre o tema que se pretende investigar.

Em 2004, Damasceno e Beserra mapearam o conhecimento produzido na área da Educação Rural, nas décadas de que ensinar e a quem, na escola, sempre 
1980 e 1990. O trabalho das autoras apresenta um levantamento das produções discentes de mestrado e doutorado do banco de resumos de teses e dissertações da Associação Nacional de Pós-graduação e Pesquisa em Educação (ANPED). Elas citam dados das produções de 1980 a 1990 e identificaram doze trabalhos na área de Educação Rural para mil trabalhos nas demais áreas da Educação. Ressaltam a queda de produções de dissertações e teses na década de 1980 em que as produções representavam $2,1 \%$ as produções, número que caiu para 0,9\% na década de 1990 . Esses números elucidam o desinteresse por essa área de estudo.

Em 2009, Silva Júnior realizou o estado da arte referente aos conhecimentos produzidos na área da educação do meio rural no período de 1996 e 2008. O autor aborda outra categoria do estado da arte no qual nos apresenta dados do conhecimento produzido na área da educação do meio rural. Ele utilizou o banco de teses de dissertações e teses produzidas nas Instituições de Ensino Superior (IES), do Estado de Minas Gerais, revistas acadêmicas, livros e documentos relacionados ao meio rural. $\mathrm{O}$ autor nos apresenta que, dos cento e vinte seis grupos cadastrados no Conselho Nacional de Desenvolvimento Científico e Tecnológico (CNPq), apenas dois se dedicavam aos estudos do meio rural. No periódico 'Educação em Revista' da Universidade Federal de Minas Gerais (UFMG), não foi encontrado nenhum artigo relacionado com a temática. Em relação aos periódicos da Universidade Federal de Uberlândia (UFU), foi encontrado um artigo relacionado à temática em 'Ensino em Re-vista'. Na Revista Educação e Filosofia foram encontrados cinco textos. Nas investigações referentes ao banco de teses e dissertações o autor utiliza como fontes o site da Capes no período de (1996-2007) e o acervo digital das seguintes universidades mineiras: UFMG, UFU, PUC-Minas e UNIUBE. Os números apresentados evidenciam a baixa produção relacionada à temática Educação do Campo. Foram identificadas 9 dissertações na UFMG; na UFU foram identificadas 7; na UFJF e PUC- Minas somente 5 trabalhos de cada uma se dedicavam ao assunto; na UNIUBE apenas 3 ligadas à educação no meio rural. $\mathrm{O}$ autor identifica apenas 2 teses publicadas na UFMG. Para Silva Júnior (2009),

os estudos apresentam dados que nos permitem concluir que a educação, no meio rural, em Minas Gerais, tem graves problemas de origem, ou seja, as escolas foram historicamente planejadas e fundamentadas nas escolas urbanas e as práticas educativas são muito distantes do cotidiano rural. (p. 218). 
As pesquisas dos autores supracitados revelam a baixa produção sobre a temática. Esse dado pouco foi alterado no cenário atual. Identificamos as produções de dissertações e teses com a temática Educação do Campo e Educação Rural nos portais de periódicos da Comissão de Aperfeiçoamento de Pessoal do Nível Superior (CAPES), no Portal Domínio Público Biblioteca digital desenvolvida em software livre e no Instituto Brasileiro de Informação em Ciência e Tecnologia (IBICT). A busca no site da CAPES e do IBICT foi realizada, a partir do campo de procura que encontramos nas plataformas de pesquisa. No portal de Domínio Público, a pesquisa pela temática em estudo foi feita em dois momentos: o primeiro pesquisando sobre a temática Educação Rural e, em seguida, uma nova busca usando o termo Educação do Campo. Em todas as três fontes utilizamos um recorte temporal que vai de 2007 a 2016. Optamos por esse recorte, pois avançaríamos em relação ao estado da arte já apresentado anteriormente por Silva Júnior (2009). Restringimos nossa pesquisa apenas para os Institutos Federais Mineiros, a fim de conhecermos e identificarmos se existem produções sobre a referida temática no Estado de Minas Gerais. Priorizamos trabalhos voltados para a área de educação.
No site da CAPES encontramos 304 produções dentro do recorte temporal estabelecido previamente, mas depois de uma leitura realizada dos resumos, identificamos apenas 9 produções que contemplavam a temática investigada. Das 9 produções, 7 delas são dissertações e 2 são teses. Os trabalhos foram identificados em três institutos federais, Universidade Federal de Uberlândia (UFU), Universidade Federal de Viçosa (UFV) e Universidade Federal Triângulo Mineiro (UFTM). As pesquisas foram produzidas em 2013, 2014 e 2015. No site do IBICT verificamos 8 trabalhos que foram defendidos nos anos de 2008, 2011, 2013, 2014, 2015 e 2016. São 6 dissertações e 2 teses. Todos foram produzidos na Universidade Federal de Uberlândia (UFU). No portal do Domínio Público, quando utilizamos o termo educação rural, encontramos 5 trabalhos sendo todos dissertações defendidas nos anos de 2007, 2008 e 2010, na Universidade Federal de Uberlândia e Universidade Federal de Viçosa. Ao pesquisarmos na mesma plataforma os termos 'educação do campo', descobrimos 2 dissertações defendidas na Pontifícia Universidade Católica de Minas Gerais (PUC-MG) e Universidade Federal de Uberlândia nos anos de 2008 e 2009. 
Ao obtermos esses dados, concordamos com Silva Júnior (2009) ao afirmar que:

\begin{abstract}
as pesquisas confirmam a importância e a necessidade de se historiarem as políticas públicas, buscando compreender o porquê de as escolas, no meio rural, não desempenharem papeis realmente significativos, voltados para a emancipação do homem campesino. Deixam clara, também, a importância da organização dos trabalhadores rurais (em especial a partir da década de 1980), na busca por trabalhadores o ensino destinado à população que vive no meio rural (p. 218).
\end{abstract}

Nesse sentido, consideramos importante conhecer e refletir sobre as diferentes temáticas abordadas nas investigações, pois podem subsidiar políticas públicas voltadas para a educação efetivada no meio rural. Das 24 produções identificadas, verificamos que os autores possuíam formação em diferentes áreas: Pedagogia, História, Geografia, Sociologia, Educação do Campo, Biologia, Direito e Ciências Sociais. Esse fato pode corroborar os diversos assuntos das dissertações e teses. Das 24 produções, 18 versavam sobre a Educação do Campo e 6 sobre a Educação Rural. Abordavam diferentes questões: ensino fundamental, médio e superior, Educação de Jovens e Adultos (EJA), Práticas, Formação, Migração, Nucleação, Agroecologia, Revolução
Verde, Currículo, Pronera, Território e Mobral.

$\mathrm{Na}$ continuação deste artigo, registramos aspectos da educação rural efetivada no município de Ituiutaba-MG, Brasil.

\section{O cenário da pesquisa: o município de Ituiutaba-MG, Brasil}

Concordamos com Silva Júnior (2012, p. 48) ao afirmar que o tempo e o espaço nos produzem. O cenário é o lugar onde as ações ocorrem, os sujeitos se formam, vivem suas histórias. O lugar tem as marcas do homem, formas, tamanhos e limites. Ao apresentar aspectos históricos, particularmente da educação efetivada no meio rural do município de Ituiutaba, não podemos perder de vista a relação com o macro, a interdependência entre "local" e "global". Como nos ensinam Nosella e Buffa (1996), não se pode permitir que a descrição pormenorizada das árvores impeça a compreensão da floresta em seu todo. As transformações ocorridas no meio rural, dos lócus da pesquisa, evidenciam algumas particularidades e diferenças, mas é possível promover comparações com outras localidades e com outras regiões.

De acordo com o IBGE, o município de Ituiutaba, em 2015, possuía 103.945 habitantes. Tem como unidade territorial, 2.598.046 km2. Faz divisa com os estados 
Sul Goiano e com noroeste de Minas, ao Sul de São Paulo e com Sul e Sudoeste de Minas e Oeste de Minas, ao Oeste e Leste de Mato Grosso do Sul. Faz parte da mesorregião do Triângulo Mineiro e Alto Paranaíba, que é uma das 12 mesorregiões do estado brasileiro, e é formada por 66 municípios agrupados em sete microrregiões, localizados na região oeste de Minas Gerais. Ocupa 15\% do território mineiro e isso a torna a segunda maior economia do Estado. A imagem a seguir registra a localização do município.

Imagem 1: Mapa localizando o município de Ituiutaba-MG, Brasil.
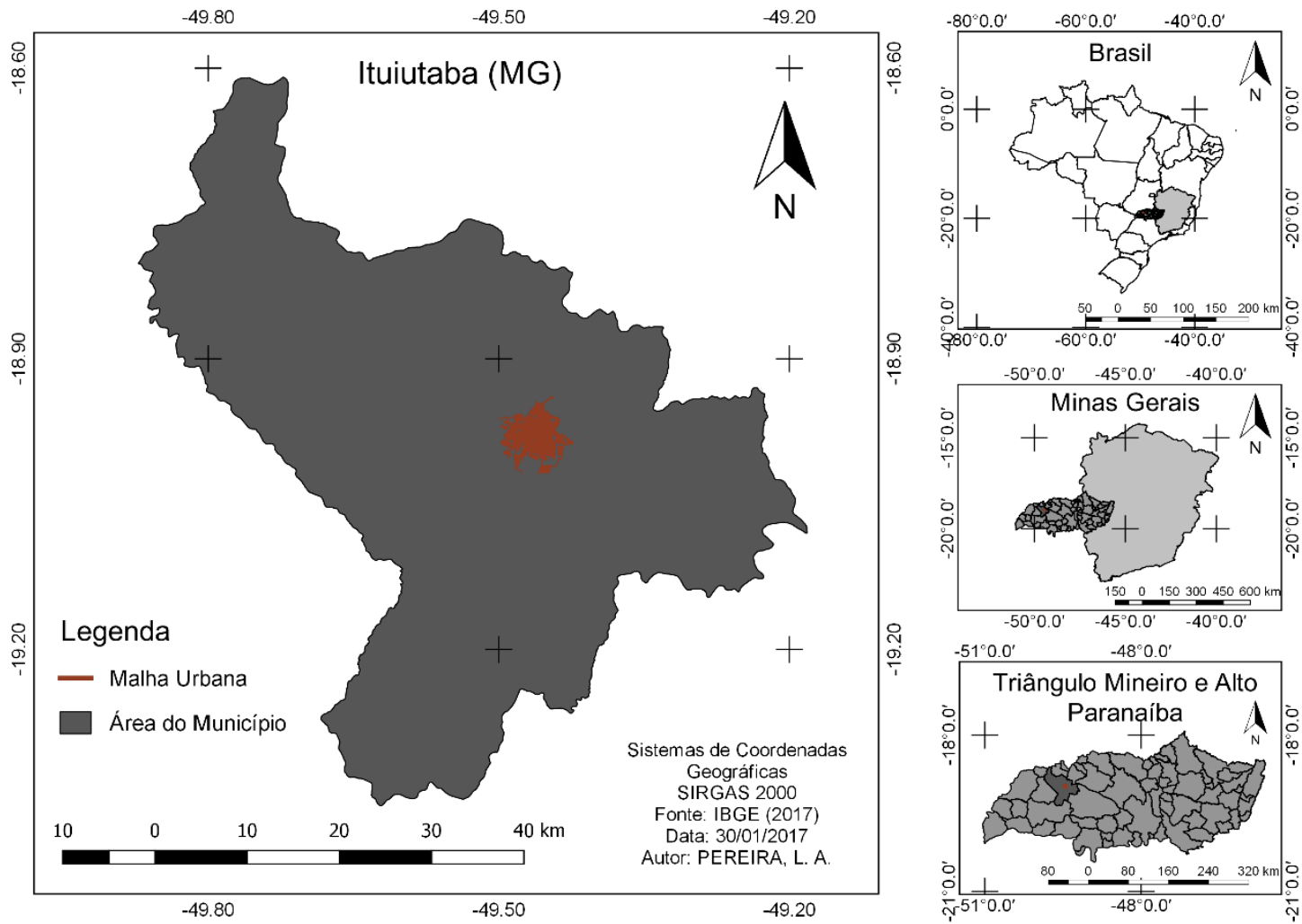

Fonte: IBGE (2016). Organização do geógrafo Lucas Alves.

Ao determos nossas reflexões acerca da educação escolar efetivada no meio rural do município de Ituiutaba, consideramos importante aprofundar o que entendemos por "rural". Não vale negar o rural, porque nele não encontramos mais, plenamente, as formas pretéritas que o caracterizavam em outros contextos. O rural se define por uma dupla característica: a predominância dos espaços naturais sobre os espaços construídos e sua conformação enquanto pequeno grupo social, onde predominam as relações de proximidade e de interconhecimento. 
O espaço rural está também associado a funções que valorizam suas características, especialmente as funções produtiva, patrimonial e residencial que o vinculam às questões alimentar, ambiental e territorial. Concordamos com Silva e Costa (2006), quando afirmam que é preciso que seja marcada a complexidade em definir o que é rural. Falar em rural na sociedade brasileira, na segunda década do século XXI, não é o mesmo que falar do rural no início do século XIX. O meio rural é marcado por uma diversidade, por uma pluralidade social, econômica, histórica e cultural. Como afirmamos na introdução deste texto, o rural é uma categoria histórica que se transformou em diferentes momentos.

No meio rural da região de Ituiutaba, no início dos anos de 1970, ainda continuava o desenvolvimento dos grãos e cereais, mas nesse contexto, verifica-se algumas transformações que podem ser explicadas em função do pacote tecnológico conhecido como Revolução Verde ${ }^{\text {ii }}$. O novo modelo possibilitou outra área de atuação, uma vez que se implantava na região o advento da tecnologia, possibilitando que a região se diversificasse, ou seja, saísse do monopólio do arroz e começasse a plantar milho, algodão e também a pecuária leiteira.
Tais mudanças ajudaram a se enquadrar no capitalismo e abriu as novas necessidades de mercado. Essa ação originou a internacionalização no campo e, daí, se deu uma expansão tecnológica que em suas necessidades e praticidades ia além da tecnologia, não dando espaço para pequenas propriedades. Nisso, podemos perceber que a Revolução Verde foi seletiva.

A estrutura da cidade da década de 1970 já se mostrava com precariedades e, nesse momento, com o declínio do arroz, a cidade passa por um vazio econômico, que somente algumas décadas depois foi preenchido com outras áreas de produção. As novas configurações do espaço agrário em diferentes lugares e regiões estavam dificultando, cada vez mais, a permanência de pequenos proprietários rurais no campo. Entre as décadas de 1970 até a década 2000, a cidade, assim como na maioria do país, passou por um intenso processo de urbanização. Com as tecnologias chegando ao campo, o município de Ituiutaba, como também o Brasil, se transformava. Os pequenos proprietários de terras não tinham mais espaço garantido. $\mathrm{O}$ acesso às tecnologias não era para todos, só para os grandes proprietários de terra. Conforme Silva Júnior (2012),

a concentração de terras é motivo de uma luta histórica no Brasil em defesa da Reforma Agrária. Com a 
modernização no campo, de forma conservadora, ou seja, mantendo a mesma estrutura fundiária e expulsando os trabalhadores do meio rural, a crise social e as possibilidades de confronto tendem a aumentar (p. 62).

Os pequenos proprietários e os trabalhadores rurais, frente ao desemprego estrutural no campo, migraram em massa para a cidade, que não possuía infraestrutura para receber esse contingente. Para essa população excedente, restavam os bairros afastados desprovidos de infraestrutura e serviços básicos de saúde e educação. Esse quadro foi-se agravando ao longo dos anos de 1980 e 1990.

O final dos anos de 1990 marca o processo de transformação do município de Ituiutaba. Nesse período é intensificada a expansão da cana-de-açúcar. Segundo a literatura científica da área, esse fato é reflexo de um cenário mundial, que passou a incentivar formas alternativas de produção de energia. Em função do plantio da cana-de-açúcar, evidencia-se a substituição de áreas de cultivo de gêneros alimentícios, como feijão, arroz, cereais, dentre outros grãos, que são à base da alimentação brasileira.

Nesse processo, a educação efetivada no meio rural também passou por mudanças. Até 1970, segundo documentos da Secretaria Municipal de Educação de
Ituiutaba, havia 70 escolas espalhadas no município. Eram escolas isoladas, ou seja, caracterizadas pela economia de dinheiro público de diversas maneiras: primeiramente, economiza na dupla exploração do professor que, além de mal remunerado, é professor, faxineiro, diretor, coordenador, cozinheiro e secretário. Existiam professores leigos, que corresponde atualmente aos anos iniciais do ensino fundamental; outros haviam concluído o que denominamos anos finais do ensino fundamental e professoras com magistério. Os documentos revelam que as salas eram multisseriadas, havia um número reduzido de estudantes por escola e eram de difícil acesso, tanto para professores como para os alunos. Não havia condições físicas e de pessoal que garantisse $\mathrm{o}$ bom funcionamento das escolas.

A partir da primeira metade dos anos de 1990, funcionavam no meio rural 60 escolas isoladas. A partir de 1993, ocorreu a primeira nucleação. O processo de nucleação é caracterizado pela união de pequenas escolas isoladas. Das 60 escolas, algumas foram desativadas e a maioria nucleada em 12 escolas. No final dos anos de 1990 aconteceu o segundo processo de nucleação, do qual resultou na permanência de 5 escolas, como segue a seguir: 
Quadro 1: As escolas localizadas no meio rural de Ituiutaba-MG, Brasil.

\begin{tabular}{|l|c|c|c|l|}
\hline \multicolumn{1}{|c|}{ Nome } & $\begin{array}{c}\text { Ano de } \\
\text { fundação }\end{array}$ & $\begin{array}{c}\text { Ano de } \\
\text { nucleação }\end{array}$ & Localização & \multicolumn{1}{c|}{ Público atendido } \\
\hline $\begin{array}{l}\text { Escola Municipal José } \\
\text { da Silva Ramos }\end{array}$ & 1970 & 1994 & $\begin{array}{c}\text { Região Córrego da } \\
\text { Chácara }\end{array}$ & $\begin{array}{l}\text { Atende a educação Infantil e } \\
\text { os anos iniciais do Ensino } \\
\text { Fundamental. }\end{array}$ \\
\hline $\begin{array}{l}\text { Escola Municipal } \\
\text { Quirino de Morais }\end{array}$ & 1941 & 1994 & $\begin{array}{c}\text { Fazenda Campo Alegre } \\
\text { (Mateirinha) }\end{array}$ & $\begin{array}{l}\text { Atende desde a Educação } \\
\text { Infantil até os anos finais do } \\
\text { Ensino Fundamental. }\end{array}$ \\
\hline $\begin{array}{l}\text { Escola Municipal } \\
\text { Bernado José Franco }\end{array}$ & 1971 & 1994 & $\begin{array}{c}\text { Região da Fazenda São } \\
\text { Lourenço }\end{array}$ & $\begin{array}{l}\text { Atende desde a Educação } \\
\text { Infantil até os anos finais do } \\
\text { Ensino Fundamental. }\end{array}$ \\
\hline $\begin{array}{l}\text { Escola Municipal } \\
\text { Francisco Antônio de } \\
\text { Lorena }\end{array}$ & 1971 & 1994 & $\begin{array}{c}\text { Região Norte da Cidade } \\
\text { nas margens do Rio } \\
\text { Tijuco (Vila Miisa) }\end{array}$ & $\begin{array}{l}\text { Atende a educação Infantil e } \\
\text { os anos iniciais do Ensino } \\
\text { Fundamental. }\end{array}$ \\
\hline $\begin{array}{l}\text { Escola Municipal } \\
\text { Arquidamiro Parreira } \\
\text { de Souza }\end{array}$ & 1970 & 1994 & Fazenda Córrego da \\
Açude. & $\begin{array}{l}\text { Atende toda Educação Básica } \\
\text { (desde a Educação Infantil ao } \\
\text { Ensino Médio) }\end{array}$ \\
\hline
\end{tabular}

Fonte: Secretaria Municipal de Educação de Ituiutaba, 2017 (organizado pelos autores).

A proposta da nucleação que se efetivou em todo o território brasileiro consistia em potencializar o espaço físico das escolas que receberiam estudantes das que seriam desativadas. A localização das escolas nucleadas seguiriam critérios geográficos. Isso significa que deveriam possuir fácil acesso e em pontos equidistantes ao longo do município. Ao mapearmos as escolas nucleadas no município de Ituiutaba, verificamos que não seguiram esse critério. Prevaleceu o interesse de grupos que tinham poder político. Dessa forma, parte do município ficou desentendida. É importante ressaltar que crianças e jovens dessas regiões estudam nas escolas periféricas localizadas no meio urbano de Ituiutaba.

Segundo Flores (2000) o processo de nucleação que ocorreu no meio rural brasileiro apresentou algumas vantagens, porém, criou outros problemas. A autora afirma que a infraestrutura melhorou, as salas de aula foram ampliadas, houve a criação de bibliotecas, sala de informática, aumentou o número de alunos e professores e diminuiu a evasão escolar. No entanto, alguns problemas históricos permaneceram, tais como o cansaço devido ao longo tempo no caminho da escola, prejuízos nos trabalhos na propriedade rural, impossibilidades de participar de atividades extras no ambiente escolar e o pouco contato entre família e professores.

Em relação à nucleação das escolas localizadas no meio rural do município de Ituiutaba, não evidenciamos grandes melhorias. A E. M. José da Silva Ramos, não possui biblioteca, sala de leitura, laboratório de informática nem quadra esportiva. As E. M. Quirino de Morais e E. M. Francisco Antônio de Lorena não 
possuem quadra de esporte. Quanto à E. M. Bernado José Franco e E. M. Arquidamiro Parreira de Souza, estas possuem laboratório de informática, biblioteca e quadra de esporte, ou seja, são as que são mais bem equipadas. No entanto, nenhuma das escolas possui acessibilidade.

A situação das escolas localizadas no meio rural revela indícios do descaso histórico em relação à população que vive no campo. Além da questão do espaço físico, no momento em que realizávamos a pesquisa na Secretaria de Educação do Município, a funcionária que nos recebeu comentou que considerava mais importante trazer os estudantes para estudar em escolas localizadas no meio urbano do que manter as escolas localizadas no meio rural, inclusive nos mostrou um documento, produzido no ano de 2016, que revelava os custos de cada estudante das escolas rurais e urbanas. Enquanto cada estudante de escolas rurais custava aos cofres do município $\$ 1.100,00$, o custo do estudante da escola urbana girava em média de $\$ 300,00$.

Além desse descaso, por meio dos documentos evidenciamos que o currículo das escolas investigadas, bem como os livros didáticos eram os mesmos utilizados nas escolas urbanas. Apenas a E. M. Arquidamiro apresentava alguns projetos voltados para as especificidades do meio rural. De forma geral, os resultados parciais dessa pesquisa sinalizam que o paradigma da Educação Rural é que se efetiva nas escolas pesquisadas.

\section{Algumas considerações}

O primeiro passo de nossa investigação nos levou a aprofundar os conhecimentos sobre os paradigmas da Educação Rural e da Educação do Campo. O primeiro, como anunciamos na introdução deste artigo, consiste em uma adaptação da educação urbana, tem caráter compensatório. O segundo considera o conhecimento como uma construção histórica, plural, complexa e dinâmica. Entende que ensinar é desafiar, despertar o desejo de buscas, ou seja, defende a autonomia dos estudantes. Esse pode ser um caminho para a aprendizagem significativa.

$\mathrm{Na}$ perspectiva da Educação do Campo a escola precisa se configurar como um espaço de diálogo crítico e reflexivo entre diferentes saberes, de reflexão, análise crítica e construção de autonomia e trabalho coletivo, mas também de articulação entre igualdade e diferença. Um espaço de busca, construção de identidades, socialização, confronto, prazer, desafio, aventura, afirmação da dimensão ética e política, reflexão sobre o 
sentido da vida e exercícios da cidadania. Nesse sentido, o papel do professor consiste em agir como agente cultural, desafiar os estudantes a ampliar horizontes, ir além da informação, construir conhecimentos e sentidos, desenvolver valores e práticas sociais.

Conscientes dos diferentes paradigmas, buscamos compreender $\mathrm{o}$ conceito de rural. Reiteramos: o rural é um contexto histórico que se transforma diante dos diferentes momentos, um espaço plural, tanto nos aspectos sociais e econômicos, quanto culturais e educacionais. $\mathrm{O}$ meio rural em ItuiutabaMG é um espaço marcado por permanências e transformações. Nesse processo, o campo ou áreas de plantio de cereais e lavouras foi sendo substituído pela cana-de-açúcar, causando uma queda no número de empregados fixos nas fazendas. Sem emprego e diante de uma escassez no campo, esse trabalhador se vê obrigado a ir para a cidade buscar alimento para sustento de sua família. Sem desconsiderar a condição material de vida, destacada como responsável pela saída do homem do campo, partimos da hipótese de que, se no meio rural se efetivasse uma educação de qualidade, talvez tais problemas poderiam ser minimizados.

Ressaltamos que, ao defendermos uma educação de qualidade, não confundimos com o conceito de qualidade total que tem como objetivo formar sujeitos empreendedores e consumidores. Tampouco com concepções tradicionais de educação: conteúdos concebidos como universais, disciplina e autoridade do professor. Mas uma educação que busque formar sujeitos, articulada a um projeto de emancipação humana; um ensino que valorize os diferentes saberes, que considere diferentes tempos e espaços, na formação dos estudantes; um ensino que tenha relação com a vida prática. É preciso reinventar a escola, essa é a proposta do paradigma da Educação do Campo.

Com o intuito de identificar o paradigma da educação escolar efetivada no meio rural do município, analisamos documentos das cinco escolas nucleadas que atendem crianças, jovens e adultos que vivem no campo. Verificamos que o processo de nucleação não impactou de forma significativa, pois permanecem as características do paradigma da Educação Rural.

Compreendemos que a escola não é simplesmente o lugar no qual se investe e produz, mas acima de tudo, o espaço social de produção de saberes e valores culturais. Nesse sentido, as escolas localizadas no meio rural precisam considerar o campo como lugar de vida e, assim, contribuir para a construção de identidades 
afirmativas. Na continuação da pesquisa propomos, a partir do contato com as diferentes comunidades escolares, mobilizar os sujeitos para a reinvenção das escolas em uma perspectiva que se aproxime do paradigma da Educação do Campo. É assim que nos sentimos nessa etapa da investigação, com a esperança de colaborar, com forte desejo de buscar mais, conhecer e participar do debate acerca da Educação do Campo, debate esse que é teórico, pedagógico e, sobretudo, político.

\section{Referências}

Araújo, F. M. L. (2006). Mulheres letradas e missionária da luz: formação da professora primária nas escolas normais rurais do Ceará - 1930-1960. (Tese de Doutorado). Universidade Federal do Ceará.

Arroyo, M. G. (2007). Políticas de formação de educadores (as) do Campo. Caderno CEDES, 27(72), 157-176.

Arroyo, M. G., Caldart, R. S., \& Molina, M. C. (Org.). (2004). Por uma Educação do Campo. (p. 7-18). Petrópolis: Vozes.

Barros, J. A. (2011). “A revisão bibliográfica: uma dimensão fundamental para o planejamento da pesquisa". Instrumento: Revista de Estudo e Pesquisa em educação, (1).

Brasil. (2002). Diretrizes Operacionais para a educação básica nas escolas do campo. Brasília, DF.

Brasil. (2005). Grupo Permanente de Trabalho de Educação do Campo. Referência para uma política nacional de
Educação do Campo. Caderno de subsídios. Brasília, DF.

Brasil. (1997). Lei de Diretrizes e Bases da Educação Nacional Nova LDB (Lei $n$. 9.394/96). Rio de Janeiro: Qualithmark Editora.

Caldart, R. S. (2004). Por uma Educação do Campo: traços de uma identidade em construção. In Arroyo, M., Caldart, R. S., \& Molina, M. C. (Org.). Por uma Educação do Campo. Petrópolis, RJ: Vozes.

Damasceno, M. N., \& Beserra, B. (2004). Estudos sobre a educação rural no Brasil: estado da arte e perspectivas. Educação $e$ Pesquisa, 30(1), 73-89.

Ferreira, N. S. A. (2002). As pesquisas denominadas "Estado da Arte". Educação \& Sociedade. (79).

Flores, M. M. L. (2000). Escola Nucleada Rural: Histórico e Perspectivas (CatalãoGO, 1998-2000) Dissertação (Dissertação de Mestrado). Universidade Federal de Uberlândia.

IBGE. (2017). Instituto Brasileiro de Geografia e Estatística. Ibge cidades. [on line] Disponível na internet via: http://ibge.gov.br/cidadesat/painel/historic o.php?codmun $=313420 \&$ search $=$ minasgerais\%7Cituiutaba\%7Cinphographics:history\&lang=_ES

Leite, S. C. (1999). Escola rural: urbanização e políticas educacionais. São Paulo: Cortez.

Nosella, P., \& Bufa, E. (1996). Schola Mater: a antiga Escola de São Carlos 1911-1933. São Carlos: EDUFSCar.

Silva Júnior, A. F. (2007). Saberes $e$ práticas de ensino de História em escolas rurais (um estudo no município de Araguari, MG, Brasil). (Dissertação de 
Mestrado). Universidade Federal de Uberlândia.

Silva Júnior, A. F. (2009). O Ensino de História no meio rural: olhares e práticas. In: Guimarães, S. (Org.). Ensinar $e$ aprender História: formação, saberes e práticas educativas. (p. 199-230). Campinas: Átomo \& Alínea.

Silva Júnior, A. F. (2012). Identidades $e$ consciência história de jovens estudantes e professores de História: um estudo em escolas no meio rural e urbano. (Tese de Doutorado). Universidade Federal de Uberlândia.

\footnotetext{
${ }^{\mathrm{i}}$ Este texto apresenta resultados de um projeto aprovado pelo edital da Chamada Universal MCTI/CNPq n 01/2016, intitulado: "Ensinar e Aprender História: um estudo em escolas localizadas no meio rural do município de Ituiutaba, MG, Brasil".

ii A expressão Revolução Verde foi criada em 1966, em uma conferência em Washington, por Wiliam Gown. As sementes modificadas e desenvolvidas nos laboratórios possuem alta resistência a diferentes tipos de pragas e doenças, seu plantio, aliado à utilização de agrotóxicos, fertilizantes, implementos agrícolas e máquinas, aumenta significativamente a produção agrícola. No Brasil, foi amplamente adotada nos anos de 1970.
}

Recebido em: 25/02/2017 Aprovado em: 12/03/2017 Publicado em: 19/04/2017
Silva Júnior, A. F., \& Borges Netto, M. (2011). Por uma Educação do Campo: percursos históricos e possibilidades. Entrelaçando: Revista eletrônica de cultura e educação, (3), 45-60.

Silva, M. V., \& Silva Júnior, A. F. (2012). Políticas educacionais para Educação do Campo: dimensões históricas e perspectivas curriculares. Revista HISTEDBR On-line, (47), 314-332.

Silva, L. H., \& Costa, V. A. (2006). Educação Rural. Presença Pedagógica, 12 (69), 25-48.
Como citar este artigo / How to cite this article / Como citar este artículo:

APA:

Silva Júnior, A. F., \& Leite, M. F. A. (2017). A educação escolar no meio rural do município de Ituiutaba-MG, Brasil: Educação Rural ou Educação do Campo? Rev. Bras. Educ. Camp., 2(1), 323-344. DOI: $\quad$ http://dx.doi.org/10.20873/uft.2525$\underline{4863.2017 \mathrm{v} 2 \mathrm{n} 1 \mathrm{p} 323}$

\section{ABNT:}

SILVA JÚNIOR, A. F.; LEITE, M. F. A. A educação escolar no meio rural do município de Ituiutaba-MG, Brasil: Educação Rural ou Educação do Campo? Rev. Bras. Educ. Camp., Tocantinópolis, v. 2, n. 1, p. $323-344$ 2017. DOI: http://dx.doi.org/10.20873/uft.25254863.2017v2n1p323 